\title{
An insight into faradaic phenomena in activated carbon investigated by means of the micro-electrode technique
}

\author{
Helena Malmberg ${ }^{1}$, Vanesa Ruiz ${ }^{2}$, Clara Blanco ${ }^{2}$, Ricardo Santamaría ${ }^{2}$, Anders \\ Lundblad $^{1}$, Pehr Björnbom ${ }^{1}$ \\ 1) Chemical Reaction Engineering, KTH-The Royal Institute of Technology, \\ Teknikringen 42, SE-100 44 Stockholm, Sweden \\ ${ }^{2)}$ Instituto Nacional del Carbón (CSIC), Apdo. 73, ES-33080 Oviedo, Spain
}

Keywords: Activated carbon, microelectrode, oxygen containing groups, quinone/hydroquinone

\section{$\underline{\text { Abstract }}$}

Cyclic voltammetry was performed on activated carbon particles in a microelectrode setup to investigate the behaviour of an activated carbon with oxygen functionalities. Quinoid type redox peaks were clearly seen in the potential region around $-0.5 \mathrm{~V}$ vs. $\mathrm{Hg} / \mathrm{HgO}$. After polarization below $-0.4 \mathrm{~V}$, an anodic peak confirms previous studies using a pristine carbon, but in the present work much higher in intensity. In addition, a corresponding cathodic peak, not previously reported, was also found. The appearance of this pair of peaks in a functionalized carbon may be connected to reversible hydrogen adsorption together with faradaic reactions involving oxygenated functional groups. 


\section{Introduction}

Activated carbon has long been investigated and used as electrode material for supercapacitor applications. There are many studies regarding the electrochemical behaviour of activated carbons, which aim to understand the role of surface area, pore size and surface chemistry. To draw definitive conclusions concerning these characteristics is not easy due to the intrinsic complexity of the material. Some carbons have shown a great contribution of Faradaic phenomena that arise from the oxygenated functional groups present in their surface [1]. The contribution of each type of functionality is different, but this is also a difficult issue. It is reported that quinoid groups may contribute to the total capacitance through faradaic reactions [2]. Additionally, further investigations into the field of hydrogen storage have pointed out the significant effect of surface functionalities $[3,4]$.

Recent work by Zuleta et al. has used the single particle microelectrode method to study the electrochemical behaviour of another material [5]. Voltammetry experiments performed in this microscopic configuration registered low current intensities, with the subsequent reduction of the ohmic drop (IR) and increased sensitivity to faradaic currents.

The material used for this study shows high specific capacitance values in aqueous electrolytes and a contribution of this capacitance is believed to arise from functional groups on the surface that contributes through a Faradaic effect [6]. Further investigations of this material were performed using the microelectrode technique in $\mathrm{KOH}$ electrolyte. 


\section{Experimental}

The activated carbon used in this study was obtained by means of chemical activation with $\mathrm{KOH}$ of a commercial mesophase pitch provided by Mitsubishi Gas Chemicals (AR24). The experimental procedure used to obtain the material and its physico-chemical characterization has been previously described [6].

\subsection{Experimental method. Microelectrode technique}

Zuleta et al. and Malmberg et al. have previously described the experimental setup for the microelectrode technique [5,7]. The basis of the method is a single carbon particle, contacted using a carbon fibre attached to a gold probe surrounded by de-aired electrolyte, thus making a working electrode. The counter electrode consists of a Ni-felt with a significantly larger surface area than the working electrode. The electrode in the microelectrode setup is solely activated carbon, i.e. no binder or additives so only the raw material of an electrode is studied without the influence of other materials.

The experiments were performed using activated carbon particles around $100 \mu \mathrm{m}$ in $6 \mathrm{M}$ potassium hydroxide $(\mathrm{KOH})$ electrolyte. The electrochemical measurement system used was an Autolab supplied by Eco Chemie BV. All the experiments were carried out at room temperature $\left(22{ }^{\circ} \mathrm{C}\right)$ and the potentials are reported vs. $\mathrm{Hg} / \mathrm{HgO}$ in the same solution.

The main electrochemical method used in this investigation into the role and formation of surface groups on activated carbon was cyclic voltammetry (CV). From the voltammograms obtained, the capacitance, the resistance of the material and the occurrence of Faradaic processes were studied. Prior to experiments in the microelectrode 
setup, the activated carbon was pre-treated in warm electrolyte $\left(\sim 40^{\circ} \mathrm{C}\right)$ for 10 minutes, followed by vacuum treatment for 10 minutes. The purpose of the pre-treatment is to ensure a better wetting, thus better ionic access to the pores, without aggressively oxidizing the active surface groups.

\section{Results and discussion}

The activated carbon used in this work is highly microporous as indicated by the textural parameters obtained from the nitrogen isotherm, shown in Table 1. The chemical activation has lead to the formation of an activated carbon with oxygenated functionalities, as indicated by the data given by elemental analysis, XPS and TPD. It is worth noting that the carbon contains a relatively high amount of $\mathrm{CO}$ evolving groups (such as phenols, ethers and carbonyl groups) which according to Alonso et al. are believed to give rise to a reversible pseudocapacitance in acidic media [8].

\subsection{Negative polarization}

Fig. 1 shows the effect of the conditioning procedure (CV between 0 and $-0.2 \mathrm{~V}$ at sweep rate of $1 \mathrm{mVs}^{-1}$ ) on the electrochemical behaviour of a single particle. After repeated cycling in a potential window (from $+0.2 \mathrm{~V}$ to $-0.4 \mathrm{~V}$ ) no significant effect on the capacitance is seen in the interval from 0 to -0.2 In this interval, the ideal electrochemical behaviour typical of electrical double layer capacitors (EDLCs) was obtained before and after the conditioning experiments.

Fig. 2 shows the performance of a particle subjected to increasingly negative polarization ( $\mathrm{CV}$ from $0 \mathrm{~V}$ to $-0.2,-0.4,-0.7,-0.9 \mathrm{~V}$, sequentially at $1 \mathrm{mVs}^{-1}$ ). For the full potential window ( 0 to $-0.9 \mathrm{~V}$ ) there are two visible peaks (III, IV). Peaks occurring at around -0.4 
$\mathrm{V}$ to $-0.5 \mathrm{~V}$ indicate a faradaic contribution (from a quinoid type redox-pair) of the material in basic media. Previous studies of the same sample using a conventional threeelectrode configuration have indicated the presence of faradaic reactions in basic media, but without such clear redox peaks [6]. Tarasevich et al. [9] also performed studies of the quinoid type chemistry in basic electrolytes and concluded that the reaction is not as straightforward as in acidic electrolyte. However, the reaction involving surface oxide groups is possible through an anion-radical reaction, together with parallel reactions.

Once the material had been subjected to negative polarization, sweeps into the anodic direction showed an increase in current as the potential reached the cut-off value $(0 \mathrm{~V})$, indicated as Peak I (beginning) in Fig. 2. This observation of a rising current led to more investigations, extending the cycling into the positive potential range. Fig. 3a shows that cycling from $+0.2 \mathrm{~V}$ to $-0.2 \mathrm{~V}$ resulted in the appearance of an unexpected pair of peaks, centered at $0 \mathrm{~V}$. These peaks were not observed when the particle was cycled in the potential range between $+0.2 \mathrm{~V}$ and $-0.4 \mathrm{~V}$ vs. $\mathrm{Hg} / \mathrm{HgO}$ prior to any other experiments, see Fig. 1. Consequently, Peaks I and II appeared only after cycling the particle into the negative region below $-0.4 \mathrm{~V}$.

\subsection{Stability of peaks}

In order to assess the nature of Peaks I and II, their stability was studied by means of repeated cycling in the $+0.2 \mathrm{~V}$ to $-0.2 \mathrm{~V}$ region. As can be seen in Fig. 3a, the intensity of the peaks is clearly reduced after several cycles, suggesting the evolution of some adsorbed species, in the way of an irreversible reaction. Repeated cycling between +0.1 and $-0.7 \mathrm{~V}$ vs. $\mathrm{Hg} / \mathrm{HgO}$ showed that the peaks in the region around $0 \mathrm{~V}$ are highly stable when charge in the particle is considered, i.e. the area enclosed by the curve, Fig. 3b. 
However, there is a shift in the potential of the peaks and there is a tendency to reduce their width with the number of cycles. These results indicate that there is a need to cycle the particle deeper into the negative potential region for the maintenance of the peaks; this finding correlates with related findings by Lombardi et al. [4].

Previous work by Zuleta et al. [5] also showed the occurrence of an anodic peak in the $0.05 \mathrm{~V}$ region after negative polarization but no corresponding peak for the cathodic sweep. Furthermore, the intensity of the peak obtained in the present work is significantly higher compared to that found by Zuleta et al. In their work, they conclude that the hydrogen produced during negative polarization (below $-0.5 \mathrm{~V}$ ) is adsorbed on the carbon surface, then oxidized in the positive range, resulting in the anodic peak. They assumed there were no other species involved in the reactions other than $\mathrm{K}^{+}, \mathrm{OH}^{-}$, and $\mathrm{H}_{2} \mathrm{O}$, due to the pristine carbon used in the study. However, in the present study the carbon is of a different nature, containing a significant amount of oxygen surface groups. Lombardi has found that the amount of hydrogen that can be adsorbed in carbonaceous materials may be enhanced by the presence of oxygenated functional groups [4]. This could explain the significantly higher intensity found for the anodic peak (Peak I, in Fig 3b). Furthermore, these functional groups are likely to participate in redox reactions similar to those proposed in equation 1 , in addition to those proposed for pristine carbon, adopted from electro-oxidation of hydrogen over Pt (equation 2) [10,11]. The reverse reaction in equation 1 is likely to be responsible for the cathodic peak (Peak II, in Fig 3b) observed at $-0.05 \mathrm{~V}$.

$$
\mathrm{C}=\mathrm{O}+2 \mathrm{C}\left(\mathrm{H}_{\mathrm{ads}}\right)+\mathrm{OH}^{-} \longleftrightarrow \mathrm{C}-\mathrm{OH}+\mathrm{H}_{2} \mathrm{O}+\mathrm{e}^{-}
$$




$$
\mathrm{C}+2 \mathrm{C}\left(\mathrm{H}_{\text {ads }}\right)+\mathrm{OH}^{-} \longleftrightarrow \mathrm{C}-\mathrm{H}+\mathrm{H}_{2} \mathrm{O}+\mathrm{e}^{-}
$$

\subsection{Positive polarization}

When potential sweeps were performed into the positive region (up to $+0.3 \mathrm{~V}$ ) the capacitance was drastically reduced, accompanied by the loss of the rectangular shape of the voltammogram (Fig. 4) which had not been observed after polarization up to $+0.2 \mathrm{~V}$, (Fig. 1). This distortion reveals serious problems of ion transport into the porous network, which may be associated with the irreversible oxidation of the carbon material. It has been described in literature that severe oxidation causes the incorporation of carboxylic groups being responsible for structural changes in the carbon [11]. In fact an increase of the oxygen content from $4 \mathrm{wt}$. \% in the starting material to $15 \mathrm{wt}$. \% after submitting it to +0.3 V during 16 hours has been measured by elemental analysis. However, further experiments have to be carried out to study these processes, and to analyse the type and amount of functionalities generated upon positive oxidation.

\subsection{Discussion of the hypothesis for Peaks I and II}

In order to compare reaction (1) with the hydrogen and oxygen electrode reactions, the electrode reactions are written based on four electrons and water on the right hand side, see reaction equations (3) - (5).

$$
\begin{array}{lll}
4 \mathrm{C}=\mathrm{O}+8 \mathrm{C}\left(\mathrm{H}_{\text {ads }}\right)+4 \mathrm{OH}^{-} & \longleftrightarrow 4 \mathrm{C}-\mathrm{OH}+4 \mathrm{H}_{2} \mathrm{O}+4 \mathrm{e}^{-} \\
2 \mathrm{H}_{2}+4 \mathrm{OH}^{-} & \longleftrightarrow 4 \mathrm{H}_{2} \mathrm{O}+4 \mathrm{e}^{-} \\
2 \mathrm{H}_{2} \mathrm{O}+4 \mathrm{OH}^{-} & \longleftrightarrow \mathrm{O}_{2}+4 \mathrm{H}_{2} \mathrm{O}+4 \mathrm{e}^{-}
\end{array}
$$


If Peaks I and II stem from reaction (3), the suggested reaction has an equilibrium potential around $0 \mathrm{~V}$ vs. $\mathrm{Hg} / \mathrm{HgO}$. We suggest that this is a reasonable hypothesis when the equilibrium potentials for reactions (4) and (5) are around -0.9 and $0.3 \mathrm{~V}$ respectively. The effect of the chemical potentials of $4 \mathrm{C}=\mathrm{O}, 8 \mathrm{C}\left(\mathrm{H}_{\mathrm{ads}}\right)$ and $4 \mathrm{C}-\mathrm{OH}$ in reaction (3) compared to the effect of the chemical potential of $2 \mathrm{H}_{2}$ in reaction (4) may have this effect on the equilibrium potential. This would mean that reaction (3) has a significant drawback compared to reaction (4) in terms of chemical potential change. A corresponding comparison between (3) and (5) suggests that the $0.3 \mathrm{~V}$ difference in equilibrium potential in this case is also reasonable.

Considering background currents, the charge balance between Peaks I and II in Fig. 3a is reasonable and this balance is retained when the peaks decrease due to desorption and diffusion of hydrogen according to Zuleta et al. discussed in [5]. The form of Peak I in Fig. 3a suggests that there may be two kinds of closely related functional groups active in Peaks I and II.

Assuming double layer charging contributes with $100-200$ F/g in Fig. 3a, the change in charge density would amount to $0.42-0.83 \mathrm{mmol} / \mathrm{g}$ from the double layer charging over a $0.4 \mathrm{~V}$ potential sweep. The areas of Peak I and II suggest that their charge is roughly equal to the double layer charging over the whole sweep, i.e. each of those peaks correspond to a charge density of $0.4-0.8 \mathrm{mmol} / \mathrm{g}$. This value of charge density arising in the peaks can be considered reasonable especially when studying the density of functional groups in the studied material (see Table 1). 


\section{Conclusions}

1) In voltammograms for microscopic particles an anodic peak around $-0.4 \mathrm{~V}$ and a corresponding cathodic peak around $-0.5 \mathrm{~V}$ are attributed to a quinoid redox couple.

2) After cycling lower than $-0.5 \mathrm{~V}$ an anodic and a cathodic peak (Peaks I and II in Fig. 3) appeared close to $0 \mathrm{~V}$ vs. $\mathrm{Hg} / \mathrm{HgO}$. Peak I may be ascribed to electrooxidation of some adsorbed hydrogen at negative potential confirming previous work, while Peak II has not previously been reported.

3) By polarization above $+0.3 \mathrm{~V}$ oxygenated surface species are formed altering the electrochemistry of the particle and causing increased resistance for ionic transport in the pores.

Acknowledgements: This work has been performed with financial support from MEC (project MAT2004-03480-C02) and FICYT (project IB05-086-C1). V. Ruiz acknowledges a predoctoral research grant from FICYT. 
Figure 1

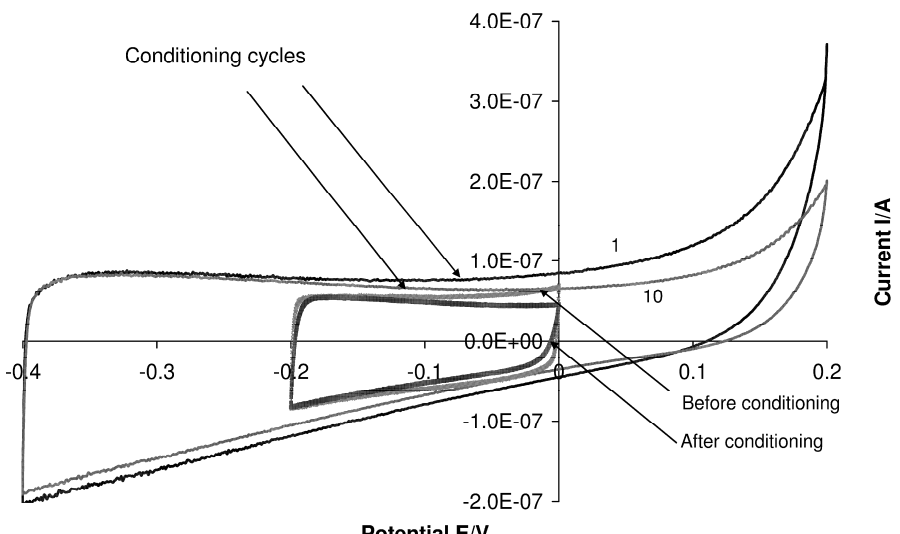

Figure 2

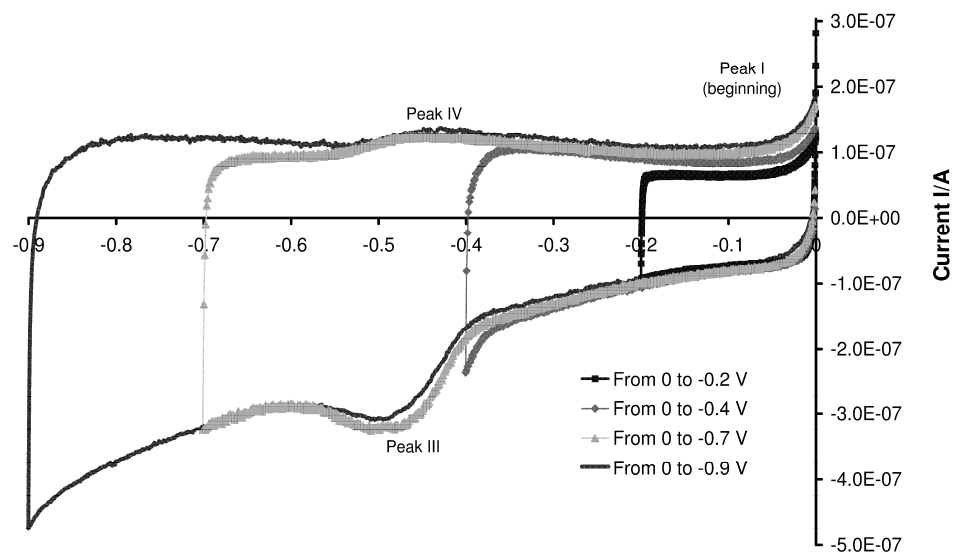

Potential E /V

Figure 3 


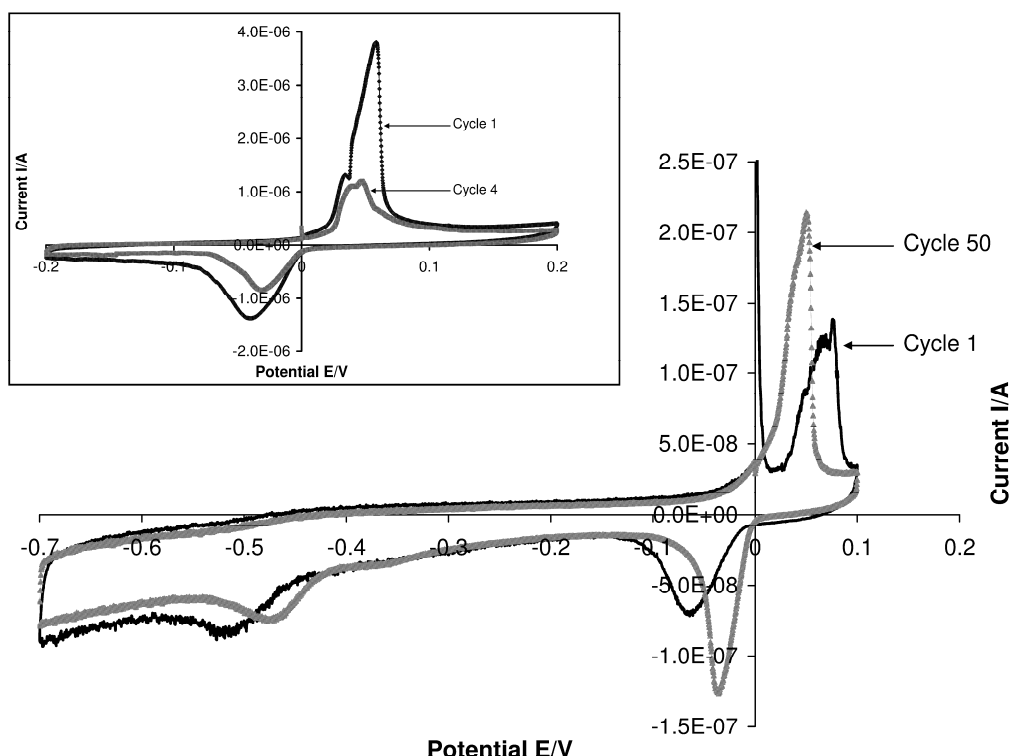

Figure 4

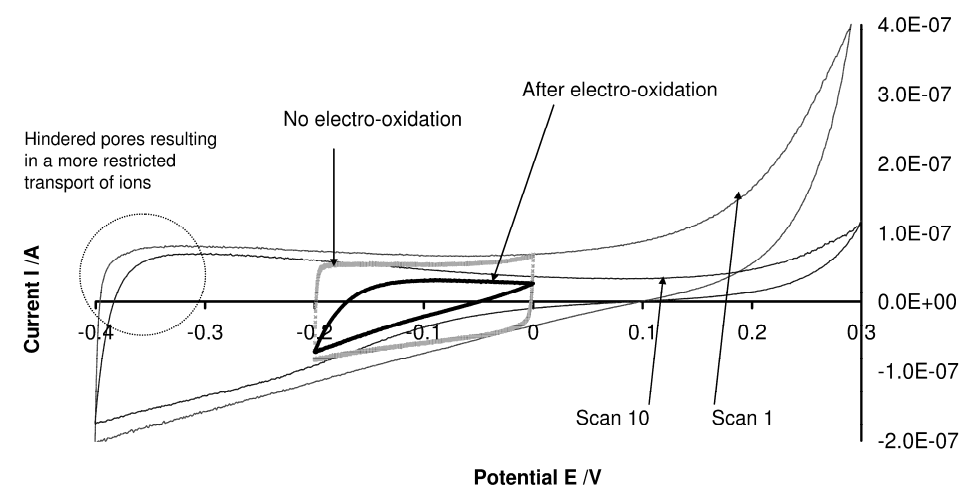




\section{References}

1 T. A. Centeno and F. Stoeckli, Electrochim. Acta, 52 (2006),560.

2. B. E. Conway, Electrochemical Supercapacitors: Scientific Fundamentals and Technological Applications, $2^{\text {nd }}$ ed., Kluwer Academic, NY, 1999.

3. K. Jurewicz, E. Frackowiak and F. Béguin, Appl. Phys. A: Mater. Sci. Process., 78 (2004), 981.

4. I. Lombardi, M. Bestetti, C. Mazzocchia, P.L. Cavallotti and U. Ducati, Electrochem. Solid-State Lett., 7 (2004), A115.

5. M. Zuleta, P. Björnbom, and A. Lundblad, J. Electrochem. Soc., 153 (1), (2006), A48.

6. V. Ruiz, C. Blanco, E. Raymundo-Piñero, V. Khomenko, F. Béguin and R. Santamaría, Electrochim. Acta, In Press, Corrected Proof, Available online 8 February 2007.

7. H. Malmberg, M. Zuleta, P. Björnbom and A. Lundblad, J. Electrochem. Soc., 153 (10) (2006), A1914.

8. A. Alonso, V. Ruiz, C. Blanco, R. Santamaria, M. Granda, R. Menendez, and S.G.E. de Jager, Carbon, 44 (2006), 441.

9. M. R. Tarasevich, V. A. Bogdanovskaya and N. M. Zagudaeva, J. Electroanal. Chem., 223 (1987), 161.

10. G. Gouterier, D.W. Kirk, P.J. Hyde and S. Srinivasan, Electrochim. Acta, 32 (1987), 995

11. M. Zuleta, P. Björnbom and A. Lundblad, J. Electrochem.Soc., 152 (2005), A270. 


\section{Table Captions}

Table 1.-Textural and chemical properties of the $\mathrm{KOH}$ activated carbon from AR24.

\section{Figure Captions}

1. The effect of repeated cycling of a particle from +0.2 to $-0.4 \mathrm{~V}$, sweep rate $1 \mathrm{mVs}^{-}$

${ }^{1}$. No Faradaic peaks are seen prior to deep cycling into more negative potentials.

2. Increasing the negative cut-off potential for a particle $\left(d_{p}=70 \mu m\right)$. Showing Faradaic behaviour attributed to quinoid-type chemistry after cut-off potential has reached more negative values than $-0.5 \mathrm{~V}$, sweep rate $1 \mathrm{mVs}^{-1}$.

3. Stability of peaks investigated by means of cyclic voltammetry, sweep rate 1 Con formato: Numeración viñetas $\mathrm{mVs}^{-1}$. (a) Insert showing the peaks centered around $0 \mathrm{~V}$, cycled between +0.2 to $0.2 \mathrm{~V}$. Degradation of peaks is visible for the first few cycles. Same particle as in Fig $2\left(d_{p}=70 \mu m\right)$. (b) The stability of the peaks for a particle $\left(d_{p}=50 \mu m\right)$ in the potential window +0.1 to $-0.7 \mathrm{~V}$, when deep cycling into the negative potentials is performed. No clear degradation of intensity in the peaks is visible, although there is a shift in location and shape.

4. Effect of positive polarization of particle $\left(\mathrm{d}_{\mathrm{p}}=100 \mu \mathrm{m}\right) \mathrm{using}$, sweep rate $1 \mathrm{mVs}^{-1}$. Eliminado: , Particle showing drastic reduction of transport properties. No Faradaic peaks are visible. 
